\title{
Landscape Context Matters When American Woodcock Select Singing Grounds: Results from a Reciprocal Transplant Experiment
}

STEPHEN J. BRENNER, ${ }^{1}$ Department of Natural Resources Science, University of Rhode Island, Kingston, Rhode Island, USA

BILL BUFFUM, Department of Natural Resources Science, University of Rhode Island, Kingston, Rhode Island, USA

BRIAN C. TEFFT, Rhode Island Department of Environmental Management, Division of Fish and Wildlife, West Kingston, Rhode Island, USA

SCOTT R. MCWILLIAMS, Department of Natural Resources Science, University of Rhode Island, Kingston, Rhode Island, USA

\begin{abstract}
The multiscale nature of habitat selection during the breeding season for migratory birds means that core-use areas (e.g., breeding territories) are selected based on their local habitat features, but these may also be influenced in some way by features within a larger-scale landscape. We conducted a reciprocal transplant experiment to test the hypothesis that habitat selection and movements of male American Woodcock (Scolopax minor) in core-use areas during the breeding season depend on the perceived quality of the surrounding landscape. We captured second-year male woodcocks $(n=19)$ at high- or low-likelihood-of-use landscapes in Rhode Island, USA, affixed each with a radio transmitter, relocated them to the opposite type of landscape, and then determined if they returned to their original site of capture or remained in the landscape to which they were relocated. Birds captured in high-likelihood landscapes and moved to low-likelihood landscapes generally returned to their original high-likelihood landscape $(5 / 7,71 \%)$, but birds captured in low-likelihood landscapes and moved to high-likelihood landscapes rarely returned to their original low-likelihood landscape $(1 / 12,8 \%)$. These results support the hypothesis that woodcock assess their surroundings relatively rapidly and subsequently make critical settlement decisions based on landscape composition. Given that woodcock choice is predicted by the woodcock-specific resource selection function, these results also provide support for the use of this tool to guide forest management for woodcock.
\end{abstract}

Proceedings of the American Woodcock Symposium 11: 123

KEY WORDS: American woodcock, landscape context, singing ground, telemetry

FUll PAPER Citation: Stephen J. Brenner, Bill Buffum, Brian C. Tefft, Scott R. McWilliams "Landscape context matters when American Woodcock select singing grounds: Results from a reciprocal transplant experiment," The Condor, 121(1), 1-11, (5 February 2019) https://doi.org/10.1093/condor/duyoo5

1 email: sjbrenner@uri.edu 